\title{
Vendor Managed Inventory: Why you need to talk to your supplier
}

\author{
Frederik Zachariassen, Henning de Haas, Sirle Bürkland \\ University of Southern Denmark (Denmark) \\ fri@sam.sdu.dk, hdh@sam.sdu.dk, seb@sam.sdu.dk
}

Received: June 2014

Accepted: July 2014

\section{Abstract:}

Purpose: The purpose of this paper is to investigate the concept of Vendor Managed Inventory (VMI) from an inter-organisational perspective. Extant literature on VMI tends to investigate the concept from a focal perspective, even though VMI has originally been born as a collaborative arrangement.

Design/methodology: The paper is based on a literature review and an empirical study. It provides a comprehensive literature review on VMI and an illustrative case study of a supplier and a buyer jointly implementing VMI.

Findings: The findings of this paper are twofold. First, a literature review uncovers that contemporary research has delimited the analysis of VMI to a focal company perspective as current VMI cost models tend not to capture the picture of the complete supply chain. Second, it demonstrates through an illustrative case study that adoption of an interorganisational approach to VMI is vital if companies are to optimize their buyer-supplier relationships.

Research limitations/implications: Future research should test the implications proposed in the empirical section, as this piece of research can be seen as exploratory case study research with the aim of analytical generalizations. 
Practical implications: The inter-organisational VMI cost perspective in supply chains should be emphasized in purchasing departments since such a perspective significantly raises the awareness of the costs incurred in a supply chain.

Originality/value: Existing research has not explicitly focused on inter-organisational costs incurred by companies implementing VMI. This study seeks to bridge this research gap.

Keywords: Supply Chain Management, VMI, inter-organisational relationships, total cost, purchasing

\section{Introduction}

In recent years the disciplines of supply chain management and logistics have gained considerable increase in scholarly attention. Such attention is due to the fact that both areas focus on creating top- as well as bottom-line improvements by streamlining the flow of material and information across the supply chain (Christopher, 1992). One of the methods for obtaining such advantages is the use of automatic replenishment programs (ARP). ARP is used in exchange relationships between buyers and suppliers, where the seller restocks inventory based on information provided by the buyer (Daugherty \& Myers, 1999). Examples of these are continuous replenishment planning (CRP) and vendor managed inventory (VMI) (Disney Potter \& Gardner, 2003; Borade \& Bansod, 2009) with the latter being occasionally referred to as consignment inventory (Dong \& Xu, 2002). Of these two examples, VMI is a unique approach, in that VMI stresses the responsibility of vendors in inventory management. Benefits emanating from this concept include but are not limited to higher selling space productivity, increased sales per store for retailers and an improved control of the bullwhip effect (Waller, Johnson \& Davis, 1999; Angulo, Nachtmann \& Waller, 2004).

Research on inventory management in general and on VMI in particular has intensified during the recent decade (Williams \& Tokar, 2008). Despite this increased focus and VMI's ostensible benefits, the concept has, however, not gained the popularity that was expected since its successful introduction and application in US retail stores, such as Wal-mart and K-mart in the early 1990's (Blatherwick, 1998). It has even been noted that "most of the accounts [of VMI] are anecdotal providing company-specific examples. Little empirical work has appeared in academic publications" (Daugherty \& Myers, 1999, pp. 63) with others stating that convincing people to engage in VMI adoptions has proven to be a "monumental task" (Pohlen \& Goldsby, 2003, pp. 566). Further, Tyan and Wee (2003) claimed that out of 10 companies only 3 to 4 achieved VMI success, with the rest of the companies forfeiting the project, while Dong, $\mathrm{Xu}$ and Dresner (2007, pp. 356) noted that "the acceptance of VMI benefits in the trade literature is [...] not universally positive." Several suggestions have been made as to what causes difficulties in VMI implementations and the subsequent use of it. These are for instance related 
to forecasting issues (Vigtil, 2007), planning nervousness (Kaipia, Korhonen \& Hartiala, 2006) and obtaining accurate estimates of production lead-times (Disney \& Towill, 2002).

The majority of the extant literature on VMI has investigated such issues via mathematical modeling, although it is continually stressed in these papers that such models carry several limitations that might cause the models to be unrealistic (Småros, Lehtonen, Appelqvist \& Holmström, 2003). Others have researched the VMI concept via case studies (e.g. Holmström, 1998). Peculiarly, these papers investigate VMI from a focal perspective, which is surprising when one notices that VMI focuses on the collaborative and therefore inter-organisational issues of managing inventory. This has lead contemporary VMI studies to place little emphasis on the inter-organisational, managerial aspects of VMI implementation, even though repeated calls have been made for such studies. For instance, Pohlen and Goldsby (2003, pp. 579) has suggested that as regards to VMI adoptions "further empirical research is required to determine how the availability of [...] information affects management decision making" and that "case study analyses will be required to capture cost and performance information across supplying and purchasing firms." In an earlier study Waller et al. (1999, pp. 198) noted that "[...] successful implementation depends heavily on sound business processes and interpersonal relationships, [where] a purely technical solutions without regard for the people involved is unlikely to deliver the benefits". In a similar vein, it has been suggested that "an area of future research that may provide benefit to inventory management is the incorporation of behavioral issues [...]" (Williams \& Moore, 2007, pp. 228). In a review of inventory management research Williams and Moore (2007, pp. 228) claim that "inventory management models [...] do not adequately account for behavioral issues and the judgment and decision making of managers. As a result, the predictive accuracy of such models may be constrained."

Answering such repeated calls for research on inter-organisational aspects of VMI would, therefore, be valuable, as it would deepen our understanding of the relevant features of VMI and buyer-supplier relationships. Since VMI originally was meant as a collaborative approach, in which both buyers and suppliers should cooperate in order to benefit from its implementation, this paper, therefore, aims to "explore how the extant literature has treated VMI and subsequently demonstrate the importance and necessity of implementing VMI from an inter-organisational perspective." The former part of the research question is answered via a comprehensive literature review, while the latter is answered through an exploratory single case study involving a focal company implementing VMI together with one of its most important customers.

To investigate the issue at hand, the paper is structured as follows. In section two, a literature review is carried out concerning VMI related contributions. The literature review reveals that the existing empirical studies tend to continuously treat VMI from a focal company perspective and ignore the inter-organisational aspects of VMI implementations. Section two also points out three central constructs of VMI that are prevailing in the existing literature. This is done 
with the aim of positioning and comparing the findings of the case study in section four in the light of the main constructs found in current literature. In section three, the methodology of a single case study is presented, while the subsequent section four explores and analyses the empirical data of the case study. Section five concludes with the findings and suggests avenues for future research.

\section{Literature review}

This section contains a brief introduction to VMI and an in-depth literature review on the subject. VMI has been researched rather intensely throughout the years with a special focus on theoretical discussions, mathematical modeling and simulation. It was not until the 1990's though that significant interest in the concept of VMI developed when companies looked at their supply chains to gain competitive advantage. While traditionally associated with the grocery sector, VMI has also been successfully implemented in a number of other areas, including the steel and electronics industries (Kuk, 2004). There are a number of benefits that VMI brings to companies and supply chains, particularly regarding dynamic inventory control, customer service and asset use. A more comprehensive description of the development of VMI and its expected benefits is provided by Disney et al. (2003).

A key element in VMI implementations is that the supplier is in control of the customer's inventory to ensure that predetermined service levels are maintained. Hence the vendor makes all replenishment decisions, dispatching a quantity of product that may be fixed or variable according to the control system used (Waller et al., 1999). In this respect, the customer effectively takes a passive role in the supply chain. From the literature definitions of VMI, it is not clear, however, whether VMI is a measure that should be taken collaboratively or if it is a solution imposed on the supplier by the customer (retailer) with only providing an effect on the latter. In the next section, this question of VMI as a focal or an inter-organizational measure will be explored.

\subsection{Review of VMI literature}

For the literature review of this study journals and papers have been searched in ScienceDirect, Wiley-Inderscience, Emerald and EBSCO HOST's databases Business Source Complete, Business Source Premiere, Academic Search Premiere and Academic Search Complete. The databases were systematically searched for the key terms "Vendor Managed Inventory" and "VMI", so that they could appear either in the title, abstract or keywords. The reference lists of the identified papers were carefully analyzed in order to include all literature that has revolved around the concept of VMI. Through the initial literature search, 70 papers were identified, from which five were excluded, as they only contained limited or sporadic references to VMI (e.g., Potter, Breite, Naim \& Vanharanta, 2004). To this reduced list of 65 
papers, six additional papers (e.g., Cooke, 1998; Achabal, Mchintyre, Smith \& Kalyanam, 2000; Cetinkaya \& Lee, 2000; Kuk, 2004; Toni \& Zamolo, 2005; Blackhurst, Craighead \& Handfield, 2006) were deemed relevant and therefore added to the list, making a total of 71 VMI-related papers identified.

The results of the literature review are presented in the below table 1 . From table 1 four different methodological approaches to the study of VMI can be discerned:

- mathematical simulation modeling,

- literature reviews/non-empirical discussions on VMI,

- quantitative data analysis and

- qualitative data analysis.

Additionally the papers can be categorized as having either a focal or an inter-organisational approach. We define a focal perspective as a research approach that investigates the concept of VMI by focusing on only one side of the buyer-supplier relationships, namely the buyer's side, thereby not explicitly investigating the suppliers side. An inter-organisational approach stresses the need for addressing both sides of the relationships either via mathematical modelling or empirical data analysis to investigate the impact of the use of VMI on both parties.

\begin{tabular}{|c|c|c|}
\hline $\begin{array}{ll} & \text { Scope } \\
\text { Methodology } & \end{array}$ & Focal & Inter-organisational \\
\hline Mathematical modeling & $\begin{array}{l}\text { Achabal et al. (2000), Cetinkaya \& Lee } \\
\text { (2000), Disney \& Towill (2002), Dong \& Xu } \\
\text { (2002), Disney et al. (2003), Småros et al. } \\
\text { (2003), Yang, Ruben \& Webster (2003), } \\
\text { Angulo et al. (2004), White \& Censlive } \\
\text { (2006), Reddy \& Vrat (2007), Sari (2007), } \\
\text { Wilson (2007), Nagarajan \& Rajagopalan } \\
\text { (2008), Southard \& Swenseth (2008), Yu, } \\
\text { Liang \& Huang (2009), Yu, Wang \& Liang } \\
\text { (2012), Yu, Hong, Zhang, Liang \& Chu } \\
\text { (2013), Chen, Lin \& Cheng (2010), Yu \& } \\
\text { Huang (2010), Lee \& Ren (2011), Dong } \\
\text { Dresner \& Yao (2013), Hariga \& Al-Ahmari } \\
\text { (2013), Hariga, Gumus, Daghfous \& Goyal } \\
\text { (2013), Hariga, Gumus \& Daghfous (2013), } \\
\text { Nia, Far \& Niaki (2013) }\end{array}$ & $\begin{array}{l}\text { Daugherty \& Myers (1999), Chan } \\
\text { Cheung, Lee \& Kwok (2006), Yu, Liang } \\
\text { \& Huang (2006), Nachiappan, } \\
\text { Gunasekaran \& Jawahar (2007), Zhang, } \\
\text { Liang, Yu \& Yu (2007), Yao \& Dresner } \\
\text { (2007, 2008), Almehdawe \& Mantin } \\
\text { (2010), Darwish \& Odah (2010), Sue- } \\
\text { Ann, Ponnambalam \& Jawahar (2012), } \\
\text { Yao, Dong \& Dresner (2012), Chen } \\
\text { (2013), Sadeghi, Mousavi, Niaki \& } \\
\text { Sadeghi (2013), Sadeghi, Sadeghi \& } \\
\text { Niaki (2014a, 2014b), Xiao \& Xu } \\
\text { (2013), Lee \& Cho (2014), Pas\&ideh, } \\
\text { Niaki \& Niknamfar (2014), Rad, Razmi, } \\
\text { Sangari \& Ebrahimi (2014) }\end{array}$ \\
\hline $\begin{array}{l}\text { Literature review/ } \\
\text { non-empirical } \\
\text { discussions on VMI }\end{array}$ & $\begin{array}{l}\text { Barratt (2003), Pohlen \& Goldsby (2003), } \\
\text { Williams \& Tokar (2008), Zammori, Braglia \& } \\
\text { Frosolini (2009) }\end{array}$ & Blatherwick (1998), Cooke (1998) \\
\hline $\begin{array}{l}\text { Quantitative data } \\
\text { analysis }\end{array}$ & $\begin{array}{l}\text { Kaipia, Holmström \& Tanskanen (2002), Toni } \\
\text { \& Zamolo (2005), Claasen, van Weele \& } \\
\text { Raaij (2008), Borade \& Bansod (2010) }\end{array}$ & $\begin{array}{l}\text { Waller et al. (1999), Kuk (2004), Dong } \\
\text { et al. (2007) }\end{array}$ \\
\hline $\begin{array}{l}\text { Qualitative data } \\
\text { analysis }\end{array}$ & $\begin{array}{l}\text { Walton (1996), Tyan \& Wee (2003), Kaipia et } \\
\text { al. (2006), Elv\&er, Sarpola \& Mattsson } \\
\text { (2007), Tanskanen, Holmström, Elfving \& } \\
\text { Talvitie (2009), Guimarães, Carvalho \& Maia } \\
\text { (2013), Stanger (2013) }\end{array}$ & $\begin{array}{l}\text { Holmström (1998), Dorling, Scott \& } \\
\text { Deakins (2005), Blackhurst et al. } \\
\text { (2006), Dorling, Scott \& Deakins } \\
\text { (2006), Vigtil (2007), Kauremaa, } \\
\text { Småros \& Holmström (2009) }\end{array}$ \\
\hline
\end{tabular}

Table 1. Results of the literature review sorted by methodology and scope 
Below, it will be shown by carefully commenting on the papers in table 1 that VMI studies have only to a limited extent provided an empirical account on the use of VMI as a collaborative initiative. There is a lack of research that investigates how both the buyer and supplier are actively involved in coordinating and cooperating with each other in VMI settings, even though empirical accounts of these relationships have repeatedly been called for in the literature.

The majority of papers (a total of 44 ) identified through the literature review deal specifically and meticulously with mathematical modeling of VMI, as for instance Wilson (2007) and Yao and Dresner (2008). Most common approaches use mathematics in order to arrive at models that could predict deterministic or stochastic demand on inventory (e.g. Lee \& Cho, 2014). Others use empirical data in order to describe VMI related aspects via simulation models (e.g. Southard \& Swenseth, 2008). Although such articles are relevant inasmuch as they contribute to highlighting how certain variables behave under fixed circumstances, they carry certain limitations in that they are only able to take into account a limited number of variables. Almost all researchers approaching the issue of optimizing VMI relationships admit that this is a limitation of these studies. For instance, Småros et al. (2003, pp.351) noted that: "[...] more case studies focusing on companies that have implemented VMI and studying the benefits they have attained as well as the problems they have faced in practice are needed. This is the only way to get reliable information on the actual processes employed by the companies as well as on the important relationship issues that are so critical to the success of collaborative approaches such as VMI."

A smaller part of the extant literature (a total of 6 papers) consists of literature reviews or normative discussions which are used to ponder various aspects of VMI. For instance, Blatherwick (1998) and Cooke (1998) discuss the diffusion of the VMI concept and its possible effects and success factors in practice. A third paper, Barratt (2003) calls for further research on verifying the actual economic benefits of VMI, while Pohlen and Goldsby (2003) investigate the managerial barriers as to why VMI is not implemented more often in firms. They conclude that further empirical research is needed on VMI application. Williams and Tokar (2008) carried out a literature review of inventory management research in major logistics journals, pointing out that further research is needed on more complex VMI settings that so far have not been modeled by mathematical means. Zammori et al. (2009) discuss how the use of standard agreements can be applied effectively in VMI settings.

Another part of the literature (a total of 7 papers) uses quantitative data to test various hypotheses. Waller et al. (1999) theoretically explain why savings potentially can accrue from VMI for both suppliers and buyers; nevertheless, they do not provide an empirical support for this. Kaipia et al. (2002) use a simulation approach based on quantitative data on inventory demand to analyse the benefits of VMI from the viewpoint of managing the replenishment process of the entire product range. They claim that "there are numerous case examples of successful VMI implementations", although the studies that they point to (e.g. Cooke, 1998 
and Holmström, 1998) do not contain empirical proof for successful VMI implementations. Kuk (2004) found that a lack of trust can be a major barrier to effective VMI adoption, while De Toni and Zamolo (2005) use a simulation model on the basis of quantitative data to argue that VMI can be a successful initiative. Their approach is purely technical, making only a minor reference to inter-organizational aspects of the VMI relationship between the buyer and supplier. On pp. 73, it is stated that "the change from the logic of traditional replenishment to VMI approach has provided significant advantages for all involved in distribution and supply chain." Nevertheless, their empirical account only focuses on the benefits of VMI on the focal company with no attention or empirical data given as to how suppliers reacted or benefited from it. Dong et al. (2007) tested various determinants of VMI adoption, while Claasen et al. (2008) investigated performance outcomes of VMI via structural equation model focusing mainly on the buyer's side. Similarly, Borade and Bansod (2010) conducted a survey for drivers and obstacles to VMI in an Indian context while focusing exclusively on the buyer's side. In conclusion, the analyses conducted in these studies provide fruitful insights on VMI adoption but do not investigate an active inter-organisational involvement between buyer and supplier.

The last group of studies relies on qualitative data (a total of 13 papers). Most of these studies limit their analysis to a focal perspective with some brief references to inter-organizational issues. For instance, Walton (1996) briefly mentions VMI in relation to electronic data interchange, while Holmström (1998) mentions some inter-organisational issues without showing an empirical evidence on these. Tyan and Wee (2003) studied an adoption of VMI between two companies in the Taiwanese grocery industry. However, they focus on the focal company, not providing an account of how the VMI implementation affected the supplier's cost structure. Dorling et al. (2005) and Dorling et al. (2006) studied key determinants of VMI projects in the New Zealand food industry, developing an organization-level framework for VMI implementations. Kaipia et al. (2006) investigated the connection between the bullwhip effect and planning nervousness in VMI related situations, while Vigtil (2007) specifically focused on the type of information exchanges that firms utilize in VMI projects. Tanskanen et al. (2009), Guimarães et al. (2013) and Stanger (2013) all investigated VMI benefits from a focal perspective with Elvander et al. (2007) categorizing different types of VMI systems via dimensions as for instance inventory locations, sourcing policies or shipment decisions.

Among the above-given list of papers, few papers can be found to involve some analysis of inter-organisational aspects of VMI. Blackhurst et al. (2006), for instance, analyse the gaps between the expected and the actual effects of two VMI initiatives. The authors audit the processes of two supply chains and suggest that shortcomings in collaboration between the partners caused material shortages and low levels of inventories in both VMI initiatives. Another study that sheds light on inter-organisational relationships is by Kauremaa et al. (2009). They provide a snap-shot picture of five different VMI dyad and report the shared benefits between suppliers and buyers. While these studies point to the importance of 
collaboration and the benefits of VMI on both parties in a supply chain, they do not provide data on the change that VMI implementation brings and collaboration between buyers and suppliers on their common goals, cost analysis and the performance of the resulting supply chain. The present paper aims to fill this gap.

In summary, the 71 papers reviewed provide mathematical modelling and empirical data mostly from a focal perspective, being limited in grasping inter-organisational relationships. The few studies that take an inter-organisational perspective on VMI implementations (e.g., Blackhurst et al., 2006; Kauremaa et al., 2009) show the effects of VMI on both the buyer and the supplier, but lack evidence on change processes of the VMI implementation that involves mutual goal setting and various offsets in costs and benefits of the changes across the sites of the buyer and the supplier.

\section{Research method}

An exploratory single case study is used to investigate VMI implementation in a focal company together with one of its key suppliers. The case study is exploratory in nature as it is used to investigate a phenomenon that lacks detailed prior research and pre-defined hypotheses (Yin, 1989). A qualitative research method was chosen since it has been suggested to be useful in complex real-life settings where the boundaries between phenomenon and context are not clearly evident and where the investigator has little control over the events (unlike an experiment), (Yin, 1989, Ellram, 1996). A VMI implementation in a buyer-supplier relationship provides such a complex setting. Barratt (2003, pp. 61-62) has also noted that "in order to gain a deeper understanding of collaborative planning, qualitative case-based research would seem to be the answer" and that "the long-term implications of collaborative planning suggest the use of longitudinal research".

Keeping this in mind a total of $2 \frac{1}{2}$ years were spent within the case company from which a sixmonth period involved an active investigation of a VMI implementation process and its consequences on the focal company and its partner. The case company was chosen for this research project as it was about to initiate a VMI implementation project together with one of its suppliers. One of the authors of this study worked in the company as a supply chain manager. While working closely together with one of the firm's key supplier the researcher was able to oversee the implementation of VMI in detail and have an adequate access to key informants of the study in both the focal company and the supplier. In this way the researcher was able to get an in-depth view of the decisions and events that took place during the VMI implementation. The other two researchers of this study remained as outsiders for the case company, being able to analyse the data without making an impact on the empirical setting. In this way a collaboration of three researchers helped to maintain an objective stance on the empirical data and avoid researcher bias. 
A confidentiality agreement was signed with both companies with the parties providing empirical data while remaining anonymous for the paper. The total hours of interviews were split between the key purchasing personnel at the case company and interviewing customers and suppliers that interacted closely with sales and procurement of the case company. The former interviews were mainly conducted with a number of strategic purchasers and a smaller number of the interviews were conducted with the heads of the purchasing division. In addition, interviews were also carried out with the key supplier to get an overview of both parties in the VMI arrangement. The interviews were designed as semi-structured and openended to keep an exploratory nature of the data inquiry.

Data were tested and validated by several means. First, in order to increase the validity of the study data triangulation was used in that several elements of the empirical data were confirmed from more than one interviewee and at different times during the research project (Eisenhardt, 1989; Lincoln \& Guba, 1985). For instance a statement concerning problematic aspects of communication between the buyer and the supper in the VMI relationships could be reported from several respondents. Second, data was analysed by identifying categories, concepts and patterns in the data through discussion rounds within the team of researchers. This strategy has been recommended for improving the reliability of the study (Lincoln \& Guba, 1985; Miles \& Huberman, 1994, pp. 278). This process was iterative so that the occurring elements and constructs of the study could be verified to a greater degree. Third, an abductive data analysis approach was used in which empirical data and theory were continuously matched throughout the research period (Kovács \& Spens, 2005). The research method employed in this study resembles the approach used by Kauremaa et al. (2009) who also used qualitative data in their study of dyadic VMI implementations. Nevertheless, the present study differs by taking a more longitudinal stand on the VMI setting. In sum, this approach to data collection fits well with the complexity of the setting and the aim of investigating VMI from an inter-organizational perspective which can only be done by successfully investigating both parties of a supply chain.

\section{VMI in an inter-organisational perspective}

The case study revolved around a six month improvement project between two Danish manufacturing companies both operating in a global setup, one supplying the other from a Chinese to a Danish manufacturing site. The supplier and the buyer decided to initiate a VMI implementation project that was set out as a two-sided cooperation in which relevant cost drivers for both the buyer and the supplier were identified. The aim of the project was to gain significant improvements in terms of delivery time, flexibility and delivery performance. 
The VMI project was split into three implementation phases:

- Initial discussions and goal setting,

- implementation,

- day-to-day operations and evaluation of the project.

In the below each phase will be reviewed and commented upon after which a section concerning implications of the case are provided in section 4.4.

\subsection{Initial discussions on the VMI project and the goal setting}

The initial work between the companies was focused on setting goals for the VMI project. The objectives of the project could be perceived as consisting of three parts:

- the mutual goals of the project,

- the objectives on the customer's side, and

- the objectives on the supplier side.

First, the overall mutual objective for the project was that the final result should be seen in a total supply chain cost perspective, meaning that the cost of the solution must balance as it did before the project with savings at the customer side covering potentially added cost at the supplier. The cost drivers considered were transaction costs in procurement and planning, warehouse handling/space and return on capital (e.g. value of goods flow and stocks). It should be noted that in this case study planning costs did not change significantly for the supplier, and this cost was therefore not included on the supplier's side. Second, objectives from the customer's side were to significantly improve delivery performance, reduce delivery lead time and increase demand flexibility, free cash tied up in raw materials inventory, reduce administrative workload in operational procurement, and save overhead costs in general. Third, objectives from the supplier side were to secure and increase turnover at the customer, gain access to more accurate demand data and thereby be able to achieve higher capacity utilization at the Chinese manufacturing site.

By looking at the cooperation and the total cost of operations from a supply chain perspective, the idea of finding a new way of operating the supply chain was fostered through a number of meetings between the supply chain managers of the two case companies, as they both were already faced with a similar challenge of reducing the cost of operating the supply chain and increasing the service to the customer. A small project group was established and given the task to analyze and document the current supply chain. The project group was also asked to 
meticulously outline two sets of goals that would be affected by the VMI implementation. The first set of goals was related to the identification of cost drivers. This was done in order to pinpoint what activities as regards to inventory management caused costs to vary at both the supplier and the customer and how these activities could then be optimized in order to cut costs and improve performance. For the supplier the primary cost drivers were freight costs, inventory costs, 3PL costs, cash flow per due days (payment terms) and potential price adjustments. For the customer the most important cost drivers were inventory costs, administration, planning and monitoring supply, cash flow per due days and potential price adjustments. Not surprisingly, freight costs and the financial cost of holding inventory were found to be highest.

The second set of goals was related to the identification of supply chain performance measures. In the meetings held between the buyer and the supplier a common set of measures were agreed upon that both parties saw as relevant to concentrate on. These were delivery service, lead time, inventory stock-outs and buffer levels, and total volume in flow. An outline of these goals were made on a mutual basis in which a simple as-is to-be analysis was carried out which will be presented in the next section 4.2 .

\subsection{Implementation of the VMI concept}

From the early stages of the improvement project the supply chain concept was characterized by a traditional buyer-seller relationship where the customer issued a purchase order and where the customer supplied ex-works from China based on an agreed lead time. The customer sent forecasts to the supplier, but these were only used as indications of the demand level. That is, no procurement or production of semi-finished goods was initiated. In the below figure 1 the supply chain concept before the VMI project can be seen.

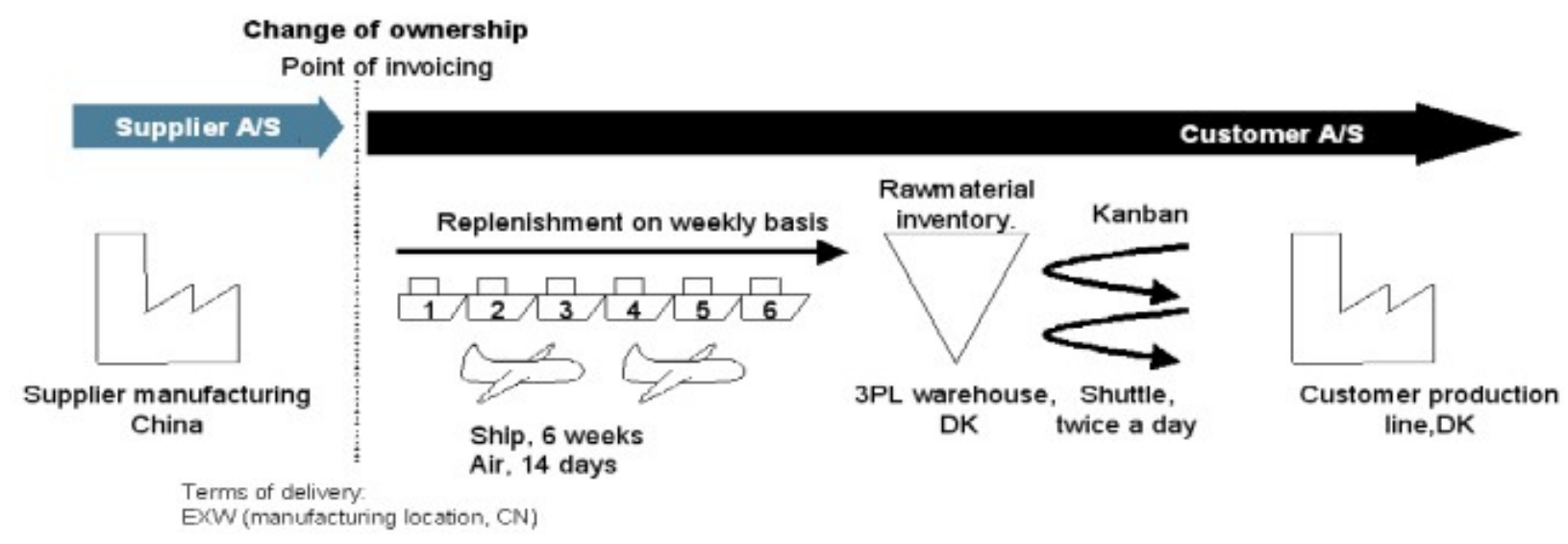

Figure 1 . The supply chain setup before the VMI change 
The mode of transportation was weekly shipment. This meant that every week the supplier sent a container to the customer. The transportation lead time including picking and customs and delivery was 5-7 weeks. When the goods arrived in Europe, they were stored in a third party logistics (3PL) warehouse, from where the production at the customer was supplied based on a Kanban pull system.

To understand the cash flow in the supply chain, it is important to notice the transaction time line, when the costs are incurred at the supplier and when they are paid for at the customer. The initial supply chain concept states that the responsibility of the goods and the point of invoicing are at shipment from the supplier in China. The payment terms in this case was 60 days net. As the customer had a raw material inventory covering 140 days of demand, the customer had to pay for the goods 135 days before usage and hold the financial value in inventory. In urgent cases, if the customer experienced sudden increases in demand, or if a quality issue was recognized, the supplier had to deliver new products to the customer by air freight which of course was much more expensive than transport by sea. As the analysis will show, the mode of transportation was chosen based on a traditional understanding of the optimization of the cost drivers in the supply chain with focus on the focal company, i.e. that the cheapest mode of transportation has to be ship and not based on a dyadic/supply chain total cost perspective. In figure 2 the supply chain setup after the VMI application is presented.

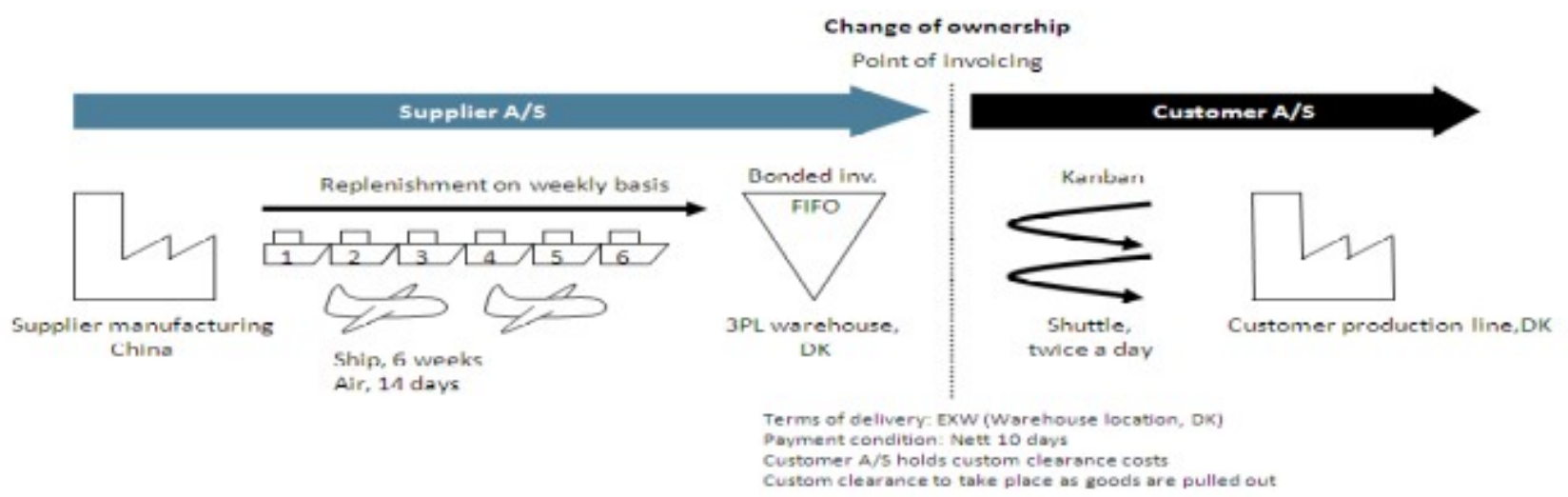

Figure 2. The supply chain setup after the VMI project

As can be seen from the figure the responsibility of the supply to the customer assembly factory was now handed over to the supplier which meant that whereas the supplier originally had the responsibility to secure goods available ex-works from the China manufacturing plant, the supplier was now responsible for securing the right products and volumes available at the raw materials inventory of the customer. This change affected both the planning and production processes at the supplier which will be discussed in section 4.3. 
A large part of the project period was dedicated to finding solutions as to how to operate the new supply chain setup. The logistical processes of the new concept, such as forecasting, ordering etc., were relatively straightforward to define. However, the success in operating the new supply-chain setup depended on the ability to find solutions to the cost implications of this new setup. As explained above, the starting point of the project was that the total cost of operation should not increase. With this in mind, the project group defined the cost drivers involved in operating the original setting and the new setup in order to be able to compare the two. A major change to the cost model of the cooperation was the shift in ownership of the goods in transit and the raw materials inventory at the customer. The cost elements in question were the value of the inventory at the customer and the value of the goods in transit. In the original setup, the transportation was organized by ship, leaving minimum 5 weeks of inventory in transit. In addition, the payment terms were called into question. The timeline of the new supply chain concept was established in order to define the cash flow of the cooperation.

The analysis made by the two companies showed that if transportation was handled by air and the inventory at the customer was tightly controlled, the cash flow effect of the change was significant. An analysis was made concerning the cost/savings at the customer and the supplier to find the cost elements changed by the change in operation. The two major cost elements that were affected by the change for the customer were found to be a reduction in inventory and the related savings in return on capital. Secondly, the administrative savings in planning were affected due to the changed setup of which the supplier is handling the planning of supply to the warehouse.

\subsection{Day-to-day operations and evaluation of the VMI setup}

Having implemented the VMI project the buyer and the supplier set out to achieve a stable day-to-day operations schedule. The impact of the VMI project could be seen in terms of financial and non-financial performance measures. The effect on the financial performance measures are illustrated in figure 3 for the supplier and the customer. 


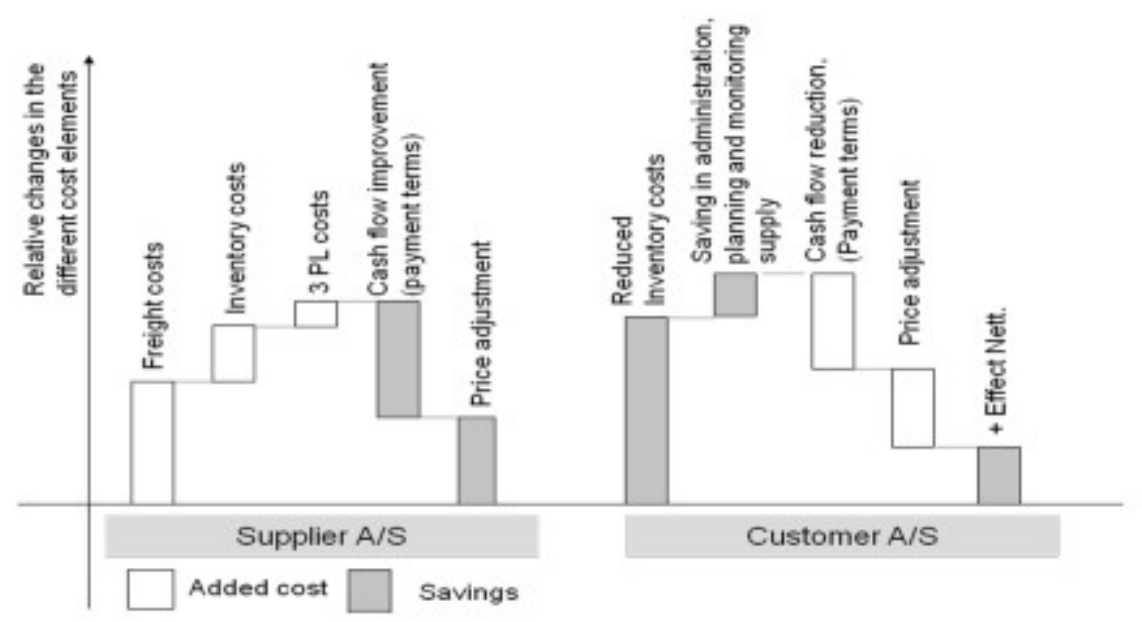

Figure 3. Effects of the VMI project on financial goals (source: provided by the case company)

As mentioned in section 4.1 the meetings between the supplier and the buyer resulted in the agreement that costs at the supplier and at the buyer should not be higher after the VMI implementation. Figure 3 highlights the achievement of this goal. At the supplier, freight costs increased because the mode of transportation changed from sea to air. In addition the supplier experienced a moderate increase in inventory and $3 \mathrm{PL}$ costs. However these added costs were offset by savings in cash flows and additionally the buyer assumed the responsibility of making for the residual added cost by letting the supplier increase the price of their products. This can also be seen on the right side of figure 3 in which the customer had an equivalent increase in the price component. In total this resulted in the supplier not incurring more costs that were not offset by savings in cash flows or an increased price in products. The customer experienced a large decline in inventory costs as the customer now could receive products much faster than before due to the change in transportation mode. The buyer and the supplier were also together able to identify cost savings in the administrative, planning and monitoring supply processes at the customer. With a decreased cash flow and the aforementioned price adjustment for the supplier the net savings effect for the customer is shown on the far right of the figure.

As mentioned in section 4.1 supply chain measures were also identified for the VMI project. Based on input from the senior supply chain managers the project group, which consisted of members from both the buyer and the supplier, was given scenarios that they needed to test during the analysis of the supply chain. For example, if the financial value of goods in transit and the large raw material inventory at the customer could finance a supply chain where all shipments were made by air, lead time could be reduced significantly, while responsiveness to changes could be increased. Areas of analysis were modes of transportation, payment terms, effect on cash flow and lead time. In addition, the project group did a mapping of the business processes in procurement and planning in the two companies to understand the hidden costs 
of the VMI setup. That is, the costs that were not directly visible in terms of inventory, transportation and handling. The changes in these supply chain performance parameters due to VMI are shown in table 2.

\begin{tabular}{|c|l|l|}
\hline Supply Chain Parameter & \multicolumn{1}{|c|}{ Before the change project } & \multicolumn{1}{c|}{ After the change project } \\
\hline Delivery service & $80 \%$ (avg. on time) & $97 \%$ (avg. on time) \\
\hline Lead time & 12 weeks & $\begin{array}{l}48 \text { h. call off time } \\
12 \text { weeks forecast commitment }\end{array}$ \\
\hline \multirow{2}{*}{ Inventory } & $\begin{array}{l}\text { Customer side: } \\
\text { Raw materials: } 20 \text { weeks } \\
\text { Goods in transit: 5-6 weeks } \\
\text { Supplier side: } \\
\text { Goods in transit: 0 weeks } \\
\text { Finished goods stock: } 2 \text { weeks }\end{array}$ & $\begin{array}{l}\text { Customer side: } \\
\text { Raw materials: } 3 \text { days } \\
\text { Goods in transit: 0 weeks } \\
\text { Supplier side: } \\
\text { Goods in transit: } 2-5 \text { weeks } \\
\text { Finished goods stock: } 3 \text { weeks }\end{array}$ \\
\hline \multirow{2}{*}{ Volume in flow (Items /Pce) } & $\begin{array}{l}30 \text { part numbers } \\
\text { Volume from 1500 pce. pr. year to } \\
25000 \text { pce. pr. year }\end{array}$ & Same, no significant change. \\
\hline
\end{tabular}

Table 2. Effects of the VMI project on supply chain performance

Table 2 shows that the effects of VMI implementation were evaluated as being positive. For instance, delivery service increased from $80 \%$ to $97 \%$. Similarly lead time changed as due to the changed mode of transportation the supplier was able to provide the buyer with a $48 \mathrm{~h}$ call off time. This affected inventory levels for the customer who was now able to minimize its raw materials stock to 3 days. The supplier, however, experienced an increase in inventory levels as goods had to be sent quickly when the customer requested an order. The added costs for the supplier were, however, offset by the customer with the price adjustments as mentioned earlier.

Before providing implications of the VMI implementation in the next section it should be briefly noted that a cost driver not considered in this analysis was the risk of obsolescence in regards to inventories. As material flow in the new setup is moving at a more rapid speed there are fewer products in the supply chain and consequently less risk of obsolescence in terms of product updates, engineering change orders (ECOs) and component changes. Therefore a more detailed analysis for the risk of obsolescence in regards to inventories was not conducted.

\subsection{Implications of the study}

In this section 4.4 significant implications of the buyer-supplier relationship are derived and discussed based on the above-given case study, with the aim of showing how an interorganisational approach to VMI differs from a focal one. The implications are discussed on the basis of the three constructs: communication, cost perspective and supply chain competencies. 
- Communication: Supply chain management literature often states that successful relationships are based on effective communication (e.g. Kulp, 2002; Dong et al., 2007). Lacking or inefficient communication is suggested to lead to conflict and inexpedient behavior due to misunderstandings (see e.g. Su, Song, Li \& Dang, 2008). In general, it can be stated that the greater the breadth and depth of this communication the more likely it is that the two parties in the relationship can be perceived as having an inter-organisational approach, whereas a relationship with lesser breadth and depth of communication can be seen as having a more focal approach (Lambert, Emmelhainz \& Gardner, 1996). Angulo et al. (2004) noted that proper information sharing in VMI relationships is important in terms of the information not being delayed or inaccurate or incomplete. Vigtil (2007) stated that sharing of inventory levels and sales forecasts are the most frequently mentioned information elements to be exchanged between buyer and supplier. The present study shows that VMI implementation projects do not only entail communication of inventory levels and sales forecasts, but an open analysis of the costs and benefits of the projects for both parties. The communication between the buyer and the supplier entails a collaborative goal setting, as well as a deeper look at each other's costs and benefits with the analysis of the overall performance of the supply-chain. Understanding of the demand patterns and need for flexibility and speed from the customer side and the limitations in production processes and procurement lead-times on the supplier side provide a common ground from which VMI changes can be negotiated and built upon as a collaborative project. Existing VMI literature have not focused upon this aspect of VMI relationships to a great extent, although some authors briefly and sparingly have touched upon the subject (Dorling et al., 2005; Vigtil, 2007).

- Cost perspective: It has been previously noted in the literature that managing costs in supply chains is vital in order to reduce total costs (Seuring, 2002, pp. 21). When implementing VMI, companies can either have a focal company perspective or a more inter-organisational perspective on costs. Existing VMI literature has mentioned some cost constructs that should be used as a guideline for the success of the implementation of VMI, but have generally limited performance measures to questions of order frequency (Waller et al., 1999), safety stock levels (Achabal et al., 2000) and fill rate (Chan et al., 2006). This signals a focus on performance optimization at the focal firm, not taking into account inter-organisational cost elements, such as cash flow changes between buyer and supplier or possible means of sharing the total costs of implementing VMI. The present study demonstrates how total costs can be understood and divided among the buyer and the supplier and how this is reached via collaborative decision-making. 
The present study emphasizes that the cost structure of a supply chain is important from a supply chain perspective not just a focal perspective. For instance, the abovegiven case study shows how in an VMI context the discussion of the mode of transportation requires an inter-organizational view of the setting as certain modes of transportation may be seen as unbeneficial when looking merely from a focal perspective, but beneficial to the supply chain in general when taking an interorganizational perspective on the relationships. For instance, the speed in material flow gives significant benefits in terms of cash flow. Contrarily, if the customer and supplier are not able to identify important financial parameters and the effects of the changes in the supply chain emanating from this, the project may likely result in a focal perspective on VMI, where the benefits of the overall supply chain remain limited besides the shifts in cost and responsibility from one part of the supply chain to another. The present study also shows that besides the traditional VMI performance measures, such as order frequency and fill rate, other measures such as cash flow improvement and reduction in overhead rates can be beneficial to the project.

- Supply chain competencies: One of the few papers that have investigated the key determinants of successful VMI adoption in regards to supply chain context and organizational skills noted that understanding the industry and supply chain factors that revolve around the implementation and use of VMI are crucial for these types of projects (see Dorling et al., 2006). These factors can amongst others be competencies in developing long-term relationships, the degree of investment in VMI and the competency to evaluate industry profitability. Underlying this Dorling et al. (2006) mention the importance of understanding the industry structure. In a similar vein Holmström (1998) noted that supply chain competencies were important when an introduction of a modified consignment order process at a focal firm using VMI was made. The present study indicates that such supply chain competencies at both buyer and supplier can result in an ability to define and measure important parameters in the implementation and use of VMI that can entail reaching common goals and save overall supply chain costs for both parties. Inter-organizational knowledge that both parties share allows them to understand the functioning of the overall supply chain and the cost structures behind the every-day interaction in a VMI setting. A lack of such competence on both or just one side of the VMI project would likely lead to a less than optimal solution. 


\section{Conclusion}

This paper sheds light on the inter-organizational nature of a VMI implementation in practice and provides three contributions to the existing literature.

- First, it highlights the tendency of the VMI research to delimit the analysis of VMI settings to the focal perspective of the supply chain. It is argued that in order to improve the existing understanding of the VMI concept scholars need to take a step further from theoretical approaches and mathematical modelling to investigate the empirical settings of VMI implementations. To understand the actual context and the benefits of this concept it is necessary to investigate the context, challenges and emerging practices across both companies in the VMI setting.

- Second, the empirical case study demonstrates how the economic benefits of a VMI setting are realized through goal setting and analysis at the inter-organizational level. It shows how certain decisions in a VMI setting may be perceived as unbeneficial when looking merely from a focal perspective, but prove to be beneficial for the supply chain in general when taking an inter-organizational perspective on VMI. This is illustrated by the cost management of a VMI project that shows the offsets in costs across the sites of the supplier and the buyer. The case study also reports on how both financial and nonfinancial drivers of performance are utilized in order to create satisfying solutions for both parties in the cooperation. This is a novel contribution, as the previous literature has been rather speculative on real life practices on cost changes and drivers of VMI performance.

- Thirdly, the study discusses the implications of the inter-organizational perspective of VMI through three constructs: communication, cost perspective and supply chain competences. It explains how an inter-organisational approach to VMI differs from a focal one and highlights the aspects of a VMI setting in regards to these three constructs. It explains how setting common goals, defining costs and identifying performance measures are reached via collaborative decision-making that requires a broader perspective and competence than that of a focal perspective.

It should be noted that as these findings are based on a single case study, they remain tentative and should be put to empirical test in further research. Nevertheless, this study provides an important reminder of the inter-organizational nature of VMI and can be considered a starting point for further studies to encompass both parties, suppliers and customers, when investigating VMI settings. For future research it is necessary to investigate the collaboration and working practices between the supplier and the buyer in more detail to improve the existing understanding of the VMI concept. Research on VMI would benefit from further investigation of issues that emerge at the inter-organizational level, such as risks, trust issues, and different areas of conflict during the negotiations and working in VMI related 
setups. Such analyses could result in successful projects as well as failures that will bring about more deeper understandings of the realities of VMI settings.

\section{References}

Achabal, D.D., Mchintyre, S.H., Smith, S.A., \& Kalyanam, K. (2000). A decision support system for vendor managed inventory. Journal of Retailing, 76(4), 430-454. http://dx.doi.org/10.1016/S0022-4359(00)00037-3

Almehdawe, E., \& Mantin, B. (2010). Vendor managed inventory with a capacitated manufacturer and multiple retailers: Retailer versus manufacturer leadership. International Journal of Production Economics, 128(1), 292-302. http://dx.doi.org/10.1016/j.ijpe.2010.07.029

Angulo, A., Nachtmann, H., \& Waller, M.A. (2004). Supply chain information sharing in a vendor managed inventory partnership. Journal of Business Logistics, 25(1), 101-120. http://dx.doi.org/10.1002/j.2158-1592.2004.tb00171.x

Barratt, M. (2003). Positioning the role of collaborative planning in grocery supply chains. International Journal of Logistics Management, 14(2), 53-66.

http://dx.doi.org/10.1108/09574090310806594

Blackhurst, J., Craighead, C.W., \& Handfield, R.B. (2006). Towards supply chain collaboration: An operations audit of VMI initiatives in the electronics industry. International Journal of Integrated Supply Management, 2(1/2), 91-105. http://dx.doi.org/10.1504/IJISM.2006.008340

Blatherwick, A. (1998). Vendor-managed inventory: fashion fad or important supply chain strategy?. Supply Chain Management: An International Journal, 3(1), 10-11.

http://dx.doi.org/10.1108/13598549810200825

Borade, A.B., \& Bansod, S. (2009). Vendor managed forecasting: A case study of small enterprises. Journal of Industrial Engineering and Management, 2(1), 153-175. http://dx.doi.org/10.3926/jiem.2009.v2n1.p153-175

Borade, A.B., \& Bansod, S. (2010). Study of vendor-managed inventory practices in Indian industries. Journal of Manufacturing Technology Management, 21(8), 1013-1038.

http://dx.doi.org/10.1108/17410381011086810

Cetinkaya, S., \& Lee, C.Y. (2000). Stock replenishment and shipment scheduling for vendormanaged inventory systems. Management Science, 46(2), 217-232.

http://dx.doi.org/10.1287/mnsc.46.2.217.11923

Chan, Y.L., Cheung, C.F., Lee, W.B., \& Kwok, S.K. (2006). Knowledge-based simulation and analysis of supply chain performance. International Journal of Computer Integrated Manufacturing, 19(1), 14-23. http://dx.doi.org/10.1080/09511920500174463 
Chen, J., Lin, I., \& Cheng, H. (2010). Channel coordination under consignment and vendormanaged inventory in a distribution system. Transportation Research Part E: Logistics and Transportation Review, 46(6), 831-843. http://dx.doi.org/10.1016/j.tre.2010.05.007

Chen, L. (2013). Dynamic supply chain coordination under consignment and vendor-managed inventory in retailer-centric B2B electronic markets. Industrial Marketing Management, 42(4), 518-531. http://dx.doi.org/10.1016/j.indmarman.2013.03.004

Christopher, M. (1992). Logistics and Supply Chain Management: Strategies for reducing cost and improving services. London: Pitman Publishing.

Claasen, M.J.T., van Weele, A.J., \& Raaij, E.M. (2008). Performance outcomes and success factors of vendor managed inventory (VMI). Supply Chain Management: An International Journal, 13(6), 406-414. http://dx.doi.org/10.1108/13598540810905660

Cooke, J.A. (1998). VMI: very mixed impact?. Logistics Management, 37(12), 51-53.

Darwish, M.A., \& Odah, O.M. (2010). Vendor managed inventory model for single-vendor multi-retailer suppply chains. European Journal of Operational Research, 204(3), 473-484. http://dx.doi.org/10.1016/j.ejor.2009.11.023

Daugherty, P.J., \& Myers, M.B. (1999). Automatic replenishment programs: An empirical examination. Journal of Business Logistics, 20(2), 63-82.

Disney, S.M., Potter, A.T., \& Gardner, B.M. (2003). The impact of vendor managed inventory on transport operations. Transportation Research Part E, 39(5), 363-380. http://dx.doi.org/10.1016/S1366-5545(03)00014-0

Disney, S.M., \& Towill, D.R. (2002). A discrete transfer function model to determine the dynamic stability of a vendor managed inventory supply chain. International Journal of Production Research, 40(1), 179-204. http://dx.doi.org/10.1080/00207540110072975

Dong, Y., \& Xu, K. (2002). A supply chain model of vendor managed inventory. Transportation Research Part E, 38(2), 75-95. http://dx.doi.org/10.1016/S1366-5545(01)00014-X

Dong, Y., Dresner, M., \& Yao, Y. (2013). Beyond information sharing: An empirical analysis of vendor-managed inventory. Production and Operations Management, 23(5), 817-828. http://dx.doi.org/10.1111/poms.12085

Dong, Y., Xu, K., \& Dresner, M. (2007). Environmental determinants of VMI adoption: An exploratory analysis. Transportation Research Part E, 43(4), 355-369.

http://dx.doi.org/10.1016/j.tre.2006.01.004 
Dorling, K., Scott, J., \& Deakins, E. (2005). An organization-level framework for the NZ food industry-its development and application. International Journal of Physical Distribution \& Logistics Management, 35(10), 728-743. http://dx.doi.org/10.1108/09600030510634580

Dorling, K., Scott, J., \& Deakins, E. (2006). Determinants of successful vendor managed inventory relationships in oligopoly industries. International Journal of Physical Distribution \& Logistics Management. 36(3), 176-191. http://dx.doi.org/10.1108/09600030610661787

Eisenhardt, K.M. (1989). Building theories from case study research. Academy of Management Review, 14(4), 532-550.

Ellram, L.M. (1996). The use of the case study method in logistics research. Journal of Business Logistics, 17(2), 93-138.

Elvander, M.S., Sarpola, S., \& Mattsson, S.-A. (2007). Framework for characterizing the design of VMI systems. International Journal of Physical Distribution \& Logistics Management, 37(10), 782-798. http://dx.doi.org/10.1108/09600030710848914

Guimarães, C.M., Carvalho, J.C., \& Maia, A. (2013). Vendor managed inventory (VMI): Evidences from lean deployment in healthcare. Strategic Outsourcing: An International Journal, 6(1), 8-24. http://dx.doi.org/10.1108/17538291311316045

Hariga, M.A., \& Al-Ahmari, A. (2013). An integrated retail space allocation and lot sizing models under vendor managed inventory and consignment stock arrangements. Computers \& Industrial Engineering, 64(1), 45-55. http://dx.doi.org/10.1016/j.cie.2012.09.013

Hariga, M., Gumus, M., Daghfous, A., \& Goyal, S.K. (2013). A vendor managed inventory model under contractual storage agreement. Computers \& Operations Research, 40(8), 2138-2144. http://dx.doi.org/10.1016/j.cor.2013.03.005

Hariga, M., Gumus, M., \& Daghfous, A. (2013). Storage constrained vendor managed inventory models with unequal shipment frequencies. Omega, In press, corrected proof.

Holmström, J. (1998). Business process innovation in the supply chain-a case study of implementing vendor managed inventory. European Journal of Purchasing \& Supply Management, 4(2-3), 127-131. http://dx.doi.org/10.1016/S0969-7012(97)00028-2

Kaipia, R., Holmström, J., \& Tanskanen, K. (2002). VMI: What are you losing if you let your customer place orders?. Production Planning and Control, 13(1), 17-25. http://dx.doi.org/10.1080/09537280110061539

Kaipia, R., Korhonen, H., \& Hartiala, H. (2006). Planning nervousness in a demand supply network: An empirical study. International Journal of Logistics Management, 17(1), 95-113. http://dx.doi.org/10.1108/09574090610663455 
Kauremaa, J., Småros, J., \& Holmström, J. (2009). Patterns of vendor-managed inventory: Findings from a multiple-case study. International Journal of Operations \& Production Management, 29(11), 1109-1139. http://dx.doi.org/10.1108/01443570911000159

Kovács, G., \& Spens, K.M. (2005). Abductive reasoning in logistics research. International Journal of Physical Distribution and Logistics Management, 35(2), 132-144. http://dx.doi.org/10.1108/09600030510590318

Kuk, G. (2004). Effectiveness of vendor-managed inventory in the electronics industry: determinants and outcomes. Information and Management, 41(5), 645-654. http://dx.doi.org/10.1016/j.im.2003.08.002

Kulp, S.C. (2002). The effect of information precision and information reliability on manufacturer-retailer relationships. The Accounting Review, 77(3), 653-677. http://dx.doi.org/10.2308/accr.2002.77.3.653

Lambert, D.M., Emmelhainz, M.A., \& Gardner, J.T. (1996). Developing and implementing supply chain partnerships. International Journal of Logistics Management, 7(2), 1-17. http://dx.doi.org/10.1108/09574099610805485

Lee, J., \& Ren, L. (2011). Vendor-managed inventory in a global environment with exchange rate uncertainty. International Journal of Production Economics, 130(2), 169-174. http://dx.doi.org/10.1016/j.ijpe.2010.12.006

Lee, J., \& Cho, R.K. (2014). Contracting for vendor-managed inventory with consignment stock and stockout-cost sharing. International Journal of Production Economics, 151, 158-173. http://dx.doi.org/10.1016/j.ijpe.2013.10.008

Lincoln, Y.S., \& Guba, E.G. (1985). Naturalistic Inquiry. Beverly Hills, CA: Sage Publications.

Miles, M.B., \& Huberman, A.M. (1994). Qualitative data analysis. Thousand Oaks, CA: Sage Publications.

Nachiappan, S.P., Gunasekaran, A., \& Jawahar, N. (2007). Knowledge management system for operating parameters in two-echelon VMI supply chains. International Journal of Production Research, 45(11), 2479-2505. http://dx.doi.org/10.1080/00207540601020478

Nagarajan, M., \& Rajagopalan, S. (2008). Contracting under vendor managed inventory systems using holding cost subsidies. 17(2), 200-210.

Nia, A.R., Far, M.H., \& Niaki, S.T.A. (2013). A fuzzy vendor managed inventory of multi-item economic order quantity model under shortage: An ant colony optimization algorithm. International Journal of Production Economics, In press, corrected proof. 
Pohlen, T.L., \& Goldsby, T.J. (2003). VMI and SMI programs: How economic value added can help sell the change. International Journal of Physical Distribution \& Logistics Management, 33(7), 565-581. http://dx.doi.org/10.1108/09600030310499268

Potter, A., Breite, R., Naim, M., \& Vanharanta, H. (2004). The potential for achieving mass customization in primary production supply chains via a unified taxonomy. Production Planning and Control, 15(4), 472-481. http://dx.doi.org/10.1080/0953728042000238746

Pasandideh, S.H.R., Niaki, S.T.A., \& Niknamfar, A.H. (2014). Lexicographic max-min approach for an integrated vendor managed inventory problem. Knowledge Based Systems, 59, 58-65. http://dx.doi.org/10.1016/j.knosys.2014.01.023

Rad, R.H., Razmi, J., Sangari, M.S., \& Ebrahimi, Z.F. (2014). Optimizing an integrated vendormanaged inventory system for a single-vendor two-buyer supply chain with determining weighting factor for vendor's ordering cost. International Journal of Production Economics, In press, accepted manuscript. http://dx.doi.org/10.1016/j.ijpe.2014.03.013

Reddy, M., \& Vrat, P. (2007). Vendor managed inventory model: A case study. Journal of Advances in Management Research, 4(1), 83-88. http://dx.doi.org/10.1108/97279810780001254

Sadeghi, J., Mousavi, S.M., Niaki, S.T.A., \& Sadeghi, S. (2013). Optimizing a multi-vendor multi-retailer vendor managed inventory problem: Two tuned meta-heuristic algorithms. Knowledge-Based Systems, 50, 159-170. http://dx.doi.org/10.1016/j.knosys.2013.06.006

Sadeghi, J., Sadeghi, S., \& Niaki, S.T.A. (2014a). A hybrid vendor managed inventory and redundancy allocation optimization problem in supply chain management: An NSGA-II with tuned parameters. Computers \& Operations Research, 41, 53-64.

http://dx.doi.org/10.1016/j.cor.2013.07.024

Sadeghi, J., Sadeghi, S., \& Niaki, S.T.A. (2014b). Optimizing a hybrid vendor managed inventory and transportation problem with fuzzy demand: An improved particle swarm optimization algorithm. Information Sciences, 272, 126-144.

http://dx.doi.org/10.1016/j.ins.2014.02.075

Sari, K. (2007). Exploring the benefits of vendor managed inventory. International Journal of Physical Distribution \& Logistics Management, 37(7), 529-545.

http://dx.doi.org/10.1108/09600030710776464

Seuring, S. (2002). Supply Chain Costing: A Conceptual Framework. In Seuring, S. \& Goldbach, M. (Eds.), Cost management in Supply Chains. New York: Physica-Verlag. http://dx.doi.org/10.1007/978-3-662-11377-6 
Småros, J., Lehtonen, J.-M., Appelqvist, P., \& Holmström, J. (2003). The impact of increasing demand visibility on production and inventory control efficiency. International Journal of Physical Distribution \& Logistics Management, 33(4), 336-354.

http://dx.doi.org/10.1108/09600030310478801

Southard, P.B., \& Swenseth, S.R. (2008). Evaluating vendor-managed inventory (VMI) in nontraditional environments using simulation. International Journal of Production Economics, 116(2), 275-287. http://dx.doi.org/10.1016/j.ijpe.2008.09.007

Stanger, S.H.W. (2013). Vendor managed inventory in the blood supply chain in Germany. Strategic Outsourcing: An International Journal, 6(1), 25-47. http://dx.doi.org/10.1108/17538291311316054

Su, Q., Song, Y., Li, Z., \& Dang, J. (2008). The impact of supply chain relationship quality on cooperative strategy. Journal of Purchasing and Supply Management, 14(4), 263-272. http://dx.doi.org/10.1016/j.pursup.2008.08.002

Sue-Ann, G., Ponnambalam, S.G., \& Jawahar, N. (2012). Evolutionary algorithms for optimal operating parameters of vendor managed inventory systems in a two-echelon supply chain. Advances in Engineering Software, 52, 47-54. http://dx.doi.org/10.1016/j.advengsoft.2012.06.003

Tanskanen, K., Holmström, J., Elfving, J., \& Talvitie, U. (2009). Vendor managed inventory (VMI) in construction. International Journal of Productivity and Performance Management, 58(1), 29-40. http://dx.doi.org/10.1108/17410400910921065

Toni, A.F.D., \& Zamolo, E. (2005). From a traditional replenishment system to vendor-managed inventory: A case study from the household electrical appliances sector. International Journal of Production Economics, 96(1), 63-79. http://dx.doi.org/10.1016/j.ijpe.2004.03.003

Tyan, J., \& Wee, H.-M. (2003). Vendor managed inventory: a survey of the Taiwanese grocery industry. Journal of purchasing \& supply management, 9(1), 11-18. http://dx.doi.org/10.1016/S0969-7012(02)00032-1

Vigtil, A. (2007). Information exchange in vendor managed inventory. International Journal of Physical Distribution \& Logistics Management, 37(2), 131-147. http://dx.doi.org/10.1108/09600030710734848

Waller, M., Johnson, M.E., \& Davis, T. (1999). Vendor-managed inventory in the retail supply chain. Journal of Business Logistics, 20(1), 183-203.

Walton, L.W. (1996). The ABC's of EDI: The role of activity-based costing (ABC) in determining EDI feasability in logistics organizations. Transportation Journal, 36(1), 43-50. 
White, A.S., \& Censlive, M. (2006). Observations on modelling strategies for vendor-managed inventory. Journal of Manufacturing Technology Management, 17(4), 496-512. http://dx.doi.org/10.1108/17410380610662915

Williams, B.D. \& Tokar, T. (2008). A review of inventory management research in major logistics journals: Themes and future directions. International Journal of Logistics Management, 19(2), 212-232. http://dx.doi.org/10.1108/09574090810895960

Williams, Z., \& Moore, R. (2007). Supply chain relationships and information capabilities: The creation and use of information power. International Journal of Physical Distribution and Logistics Management, 37(6), 469-483. http://dx.doi.org/10.1108/09600030710763387

Wilson, M.C. (2007). The impact of transportation disruptions on supply chain performance. Transportation Research Part E, 43(4), 295-320. http://dx.doi.org/10.1016/j.tre.2005.09.008

Yang, K., Ruben, R.A., \& Webster, S. (2003). Managing vendor inventory in a dual level distribution system. Journal of Business Logistics, 24(2), 91-108.

http://dx.doi.org/10.1002/j.2158-1592.2003.tb00047.x

Yao, Y., \& Dresner, M. (2007). Supply chain integration in vendor-managed inventory. Decision Support Systems, 43(2), 663-674. http://dx.doi.org/10.1016/j.dss.2005.05.021

Yao, Y., \& Dresner, M. (2008). The inventory value of information sharing, continuous replenishment, and vendor-managed inventory. Transportation Research Part E, 44(3), 361-378. http://dx.doi.org/10.1016/j.tre.2006.12.001

Yao, Y., Dong, Y., \& Dresner, M. (2012). Supply chain learning and spillovers in vendor managed inventory. Decision Sciences, 43(6), 979-1001. http://dx.doi.org/10.1111/j.15405915.2012.00379.x

Yin, R.K. (1989). Case study research. California: Newbury Park.

Yu, Y., Liang, L., \& Huang, G.Q. (2006). Leader-follower game in vendor-managed inventory system with limited production capacity considering wholesale and retail prices. International Journal of Logistics: Research and Applications, 9(4), 335-350.

http://dx.doi.org/10.1080/13675560600836910

Yu, Y., Liang, L., \& Huang, G.Q. (2009). Stackelberg game-theoretic model for optimizing advertising, pricing and inventory policies in vendor managed inventory (VMI) production supply chains. Computers \& Industrial Engineering, 57(1), 368-382.

http://dx.doi.org/10.1016/j.cie.2008.12.003 
Yu, Y., \& Huang, G. (2010). Nash game model for optimizing market strategies, configuration of platform products in a Vendor Managed Inventory (VMI) supply chain for a product family. European Journal of Operational Research, 206(2), 361-373.

http://dx.doi.org/10.1016/j.ejor.2010.02.039

Yu, Y., Wang, Z., \& Liang, L. (2012). A vendor managed inventory supply chain with deteriorating raw materials and products. International Journal of Production Economics, 136(2), 266-274. http://dx.doi.org/10.1016/j.ijpe.2011.11.029

Yu, Y., Hong, Z., Zhang, L.L., Liang, L., \& Chu, C. (2013). Optimal selection of retailers for a manufacturing vendor in a vendor managed inventory system. European Journal of Operational Research, 225(2), 273-284. http://dx.doi.org/10.1016/j.ejor.2012.09.044

Xiao, T., \& Xu, T. (2013). Coordinating price and service level decisions for a supply chain with deteriorating item under vendor managed inventory. International Journal of Production Economics, 145(2), 743-752. http://dx.doi.org/10.1016/j.ijpe.2013.06.004

Zammori, F., Braglia, M., \& Frosolini, M. (2009). A standard agreement for vendor managed inventory. Strategic Outsourcing: An International Journal, 2(2), 165-189. http://dx.doi.org/10.1108/17538290910973376

Zhang, T., Liang, L., Yu, Y., \& Yu, Y. (2007). An integrated vendor-managed inventory model for a two-echelon system with order cost reduction. International Journal of Production Economics, 109(1-2), 241-253. http://dx.doi.org/10.1016/j.ijpe.2006.12.051

Article's contents are provided on a Attribution-Non Commercial 3.0 Creative commons license. Readers are allowed to copy, distribute and communicate article's contents, provided the author's and Journal of Industrial Engineering and Management's names are included. It must not be used for commercial purposes. To see the complete license contents, please visit http://creativecommons.org/licenses/by-nc/3.0/. 